\title{
Toughness Calculation of Postfire Normal Concrete
}

\author{
Qingyang Chen, ${ }^{1}$ Anjing Tang, ${ }^{2}$ and Zhoudao Lu ${ }^{1}$ \\ ${ }^{1}$ College of Civil Engineering, Tongji University, Shanghai 200092, China \\ ${ }^{2}$ College of Urban Construction and Administration, Yunnan University, Kunming 650091, China
}

Correspondence should be addressed to Anjing Tang; taj531@126.com

Received 5 October 2013; Revised 7 January 2014; Accepted 7 January 2014; Published 19 February 2014

Academic Editor: Filippo Berto

Copyright (C) 2014 Qingyang Chen et al. This is an open access article distributed under the Creative Commons Attribution License, which permits unrestricted use, distribution, and reproduction in any medium, provided the original work is properly cited.

Fracture tests of postfire normal concrete with ten temperatures up to $600^{\circ} \mathrm{C}$ are implemented. Residual fracture toughness using analytical method is determined. Two situations are divided at critical load when calculating the cohesive fracture toughness. The initial and critical fracture toughness could be calculated from the complete load-crack opening displacement curves. Finally, the validation of double- $K$ fracture model to the postfire concrete specimens is proved.

\section{Introduction}

The fracture process of concrete structures underwent three main stages: (i) crack initiation, (ii) stable crack propagation, and (iii) unstable fracture. Accordingly, the double-K fracture criterion initially introduced by Xu and Reinhardt [1] showed the crack initiation, crack propagation, and failure during a fracture process until the maximum load is reached. And the two size-independent parameters, initial cracking toughness, $K_{I}^{\text {ini }}$, and unstable fracture toughness, $K_{I}^{\text {un }}$, can be used to study the crack propagation of concrete.

In order to determine the double- $K$ fracture parameters analytically $[2,3]$ the value of cohesion toughness $K_{I}^{c}$ due to cohesive stress distribution in the fictitious fracture zone was computed using method proposed by Jenq and Shah [4]. The influences of geometrical parameter [5-7] and size effect [2,3, 8 ] on fracture toughness were studied by various researchers. It was found that the influence of $a_{o} / D$ ratio and shape of test specimen on the values of fracture parameters were relatively less than the one of size effect.

The influence of temperature on the fracture parameters was also considered by several researchers, but mainly on the fracture energy and material brittleness [9-13] and relatively fewer discussions on the fracture toughness $[14,15]$. In the present paper, the calculation of residual fracture toughness of concrete is carried out. Wedge-splitting experiments of totally ten temperatures varying from $20^{\circ} \mathrm{C}$ to $600^{\circ} \mathrm{C}$ are implemented. The specimen sizes are of $230 \times 200 \times 200 \mathrm{~mm}$ with initial-notch depth ratios of 0.4 . The validation of double- $K$ fracture model to the postfire normal concrete is proved.

\section{Analytical Determination of Cohesive Fracture Toughness}

2.1. Effective Crack Extension Length and Residual Young's Modulus. The linear asymptotic superposition assumption was considered in the analytical method presented by Reinhardt et al. [2, 3] to introduce the concept of linear elastic fracture mechanics for calculating the double- $K$ fracture parameters. Detailed explanation of the above assumption can be found elsewhere [2].

Based on this assumption, the value of the equivalentelastic crack length for WS specimen is expressed as

$$
a=\left(h+h_{0}\right)\left\{1-\left(\frac{13.18}{E \cdot b \cdot c+9.16}\right)^{1 / 2}\right\}-h_{0},
$$

where $c=\mathrm{CMOD} / P$ is the compliance of specimens and $b$ is specimens thickness; $h$ is specimens height and $h_{0}$ is the thickness of the clip gauge holder. For calculation of critical value of equivalent-elastic crack length $a_{c}$, the value of crack mouth opening displacement (CMOD) and $P$ is taken as $\mathrm{CMOD}_{c}$ and $P_{u}$, respectively. 


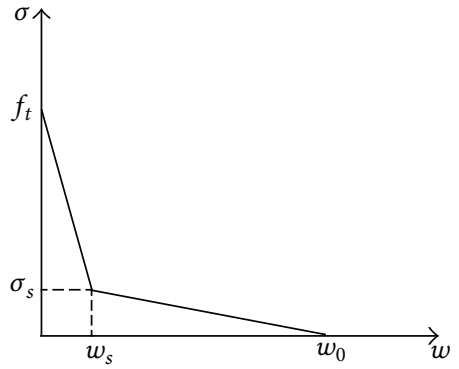

FIGURE 1: The bilinear softening traction-separation law.

The residual Young's modulus $E$ is calculated using the $P$ CMOD curve as

$$
E=\frac{1}{b c_{i}}\left[13.18 \times(1-\alpha)^{2}-9.16\right]
$$

where $c_{i}=\mathrm{CMOD}_{\text {ini }} / P_{\text {ini }}$ is the initial compliance before cracking, $\alpha=\left(a_{0}+h_{0}\right) /\left(h+h_{0}\right)$. The values of critical equivalent-elastic crack length $a_{c}$ and residual Young's modulus $E$ are listed in Table 1.

\subsection{Crack Opening Displacement along the Fracture Process} Zone. Since the cohesive stress distribution along the fracture process zone depends on the crack opening displacement and the specified softening law, it is important to know the value of crack opening displacement along the fracture line. It is difficult to measure directly the value of COD along the fracture process zone; for practical purposes the value of $\operatorname{COD}(x)$ at the crack length $x$ is computed using the following expression [3]:

$\operatorname{COD}(x)$

$$
=\operatorname{CMOD}\left\{\left(1-\frac{x}{a}\right)^{2}+\left(1.018-1.149 \frac{a}{h}\right)\left[\frac{x}{a}-\left(\frac{x}{a}\right)^{2}\right]\right\}^{1 / 2} .
$$

For calculation of critical value of crack tip opening displacement $\mathrm{CTOD}_{c}$, the value of $x$ and $a$ (see Figure 3 ) in (3) is taken to be $a_{o}$ and $a_{c}$, respectively. The value of cohesive stress along the fictitious fracture zone to the corresponding crack opening displacement is evaluated using bilinear stressdisplacement softening law as given in (6).

\subsection{Softening Traction-Separation Law of Postfire Concrete.} The softening traction-separation law is a prerequisite determine the double- $K$ fracture parameters, at room temperature; many expressions have been proposed based on direct tensile tests [16-20]. Based on numerical studies, simplified bilinear expressions for the softening traction-separation law (illustrated in Figure 1) were suggested by Petersson in 1981 [16], Hilsdorf and Brameshuber in 1991 [19], and Phillips and Zhang in 1993 [20]. The area under the softening curve was defined as the fracture energy $G_{F}$. Therefore, one could get the following equation:

$$
G_{F}=\frac{1}{2}\left(f_{t} w_{s}+\sigma_{s} w_{0}\right)
$$

where $f_{t}$ is tensile strength of postfire specimens, $w_{s}$ is the crack width at break point of softening curve, $\sigma_{s}$ is the cohesive stress at the break point of softening curve, and $w_{0}$ is crack width at stress-free point.

As a consequence, a general form of the simplified bilinear expression of the softening traction-separation law is given as follows:

$$
\begin{gathered}
\sigma=f_{t}-\frac{\left(f_{t}-\sigma_{s}\right) w}{w_{0}}, \quad 0 \leq w \leq w_{s} \\
\sigma=\frac{\sigma_{s}\left(w_{0}-w\right)}{\left(w_{0}-w_{s}\right)}, \quad w_{s} \leq w \leq w_{0} \\
\sigma=0, \quad w \geq w_{0} .
\end{gathered}
$$

Different values of the break point $\left(\sigma_{s}, w_{s}\right)$ and the crack width $w_{0}$ at stress-free point were used for the expression proposed by different researchers. In the present work, the bilinear softening function of concrete proposed by Petersson is used for postfire specimens:

$$
\begin{gathered}
\sigma_{s}=\frac{f_{t}}{3}, \\
w_{s}=\frac{0.8 G_{F}}{f_{t}}, \\
w_{0}=\frac{3.6 G_{F}}{f_{t}} .
\end{gathered}
$$

2.4. Determination of Stress Intensity Factor Caused by Cohesive Force. The standard Green's function [21] for the edge cracks with finite width of plate subjected to a pair of normal forces is used to evaluate the value of cohesive toughness. The general expression for the crack extension resistance for complete fracture associated with cohesive stress distribution in the fictitious fracture zone for Mode I fracture is given as follows:

$$
K_{I}^{c}=\int_{a_{0}}^{a} \frac{2 \sigma(x) F(x / a, a / h)}{\sqrt{\pi a}} d x
$$

where

$$
\begin{aligned}
F\left(\frac{x}{a}, \frac{a}{h}\right)= & \frac{3.52(1-x / a)}{(1-a / h)^{3 / 2}}-\frac{4.35-5.28 x / a}{(1-a / h)} \\
& +\left\{\frac{1.30-0.30(x / a)^{3 / 2}}{\sqrt{1-(x / a)^{2}}}+0.83-1.76 \frac{x}{a}\right\} \\
& \times\left\{1-\left(1-\frac{x}{a}\right) \frac{a}{h}\right\}
\end{aligned}
$$

and $\sigma(x)$ is the cohesive force at crack length $x$, see Figure 3, and its expression is shown in (9) or (11).

At critical condition the value of $a$ is taken to be $a_{c}$ in (7) and (8). The integration of (8) is done by using Gauss-Chebyshev quadrature method because of existence of singularity at the integral boundary. 


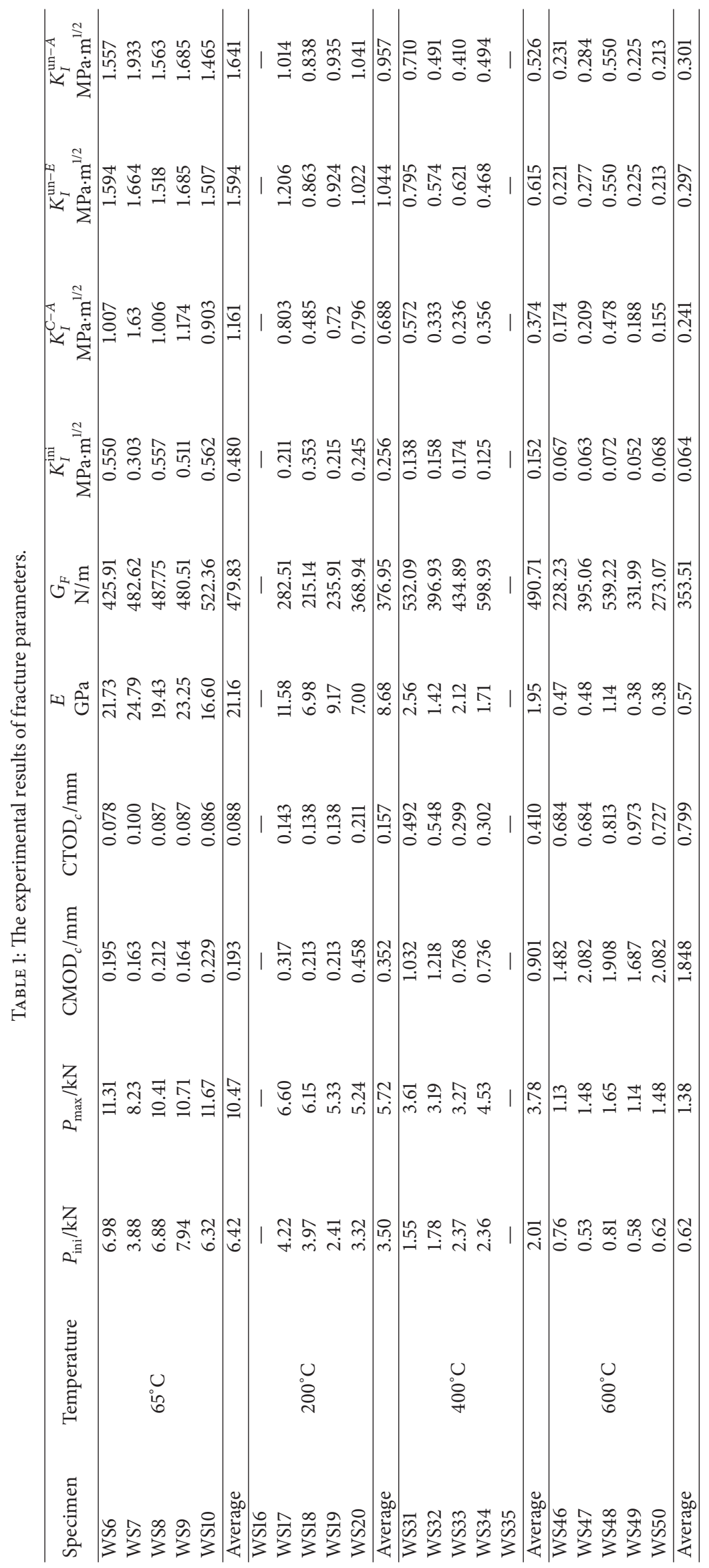




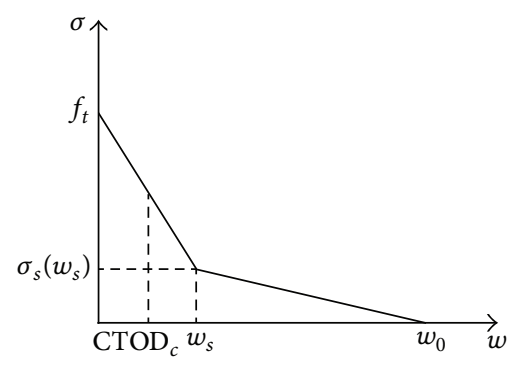

(a) When $\mathrm{CTOD}_{c} \leq w_{s}$

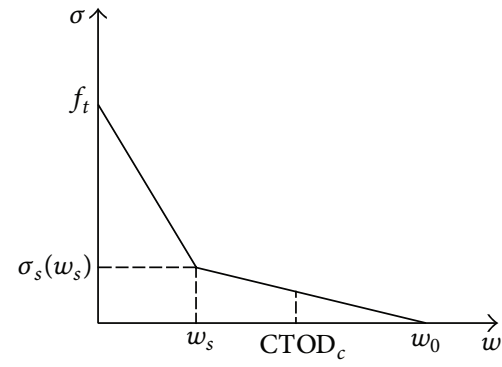

(b) When $\mathrm{CTOD}_{c}>w_{s}$

FIgure 2: Two different situations for $\mathrm{CTOD}_{c}$ and $w_{s}$.

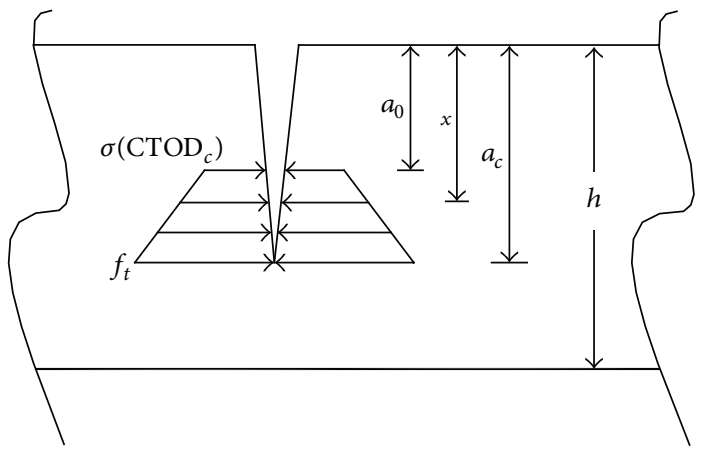

(a) The linear distribution of cohesive force

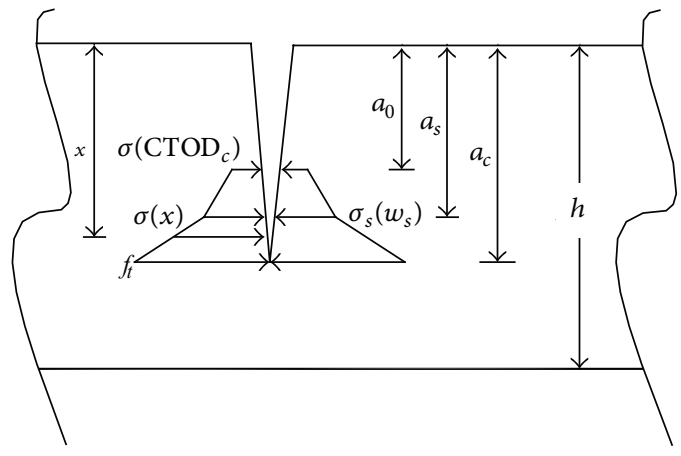

(b) The bilinear distribution of cohesive force

Figure 3: Cohesive force distribution along the crack length at critical load.

As shown in Figure 2, two conditions at critical load, that is, $\mathrm{CTOD}_{c} \leq w_{s}$ and $w_{s} \leq \mathrm{CTOD}_{c} \leq w_{c}$, may arise at the notch tip while using bilinear softening function. For specimens subjected to temperatures less than $120^{\circ} \mathrm{C}$, the critical CTOD ${ }_{c}$ is less than $w_{s}$, whereas, for temperatures higher than $120^{\circ} \mathrm{C}$, the critical CTOD ${ }_{c}$ is wider than $w_{s}$.

(A) When the critical $\mathrm{CTOD}_{c}$ corresponding to maximum load $P_{u}$ is less than $w_{s}$ as shown in Figure 2(a), the distribution of cohesive stress along the fictitious fracture zone is approximated to be linear as shown in Figure 3(a). The variation of cohesive stress along the fictitious fracture zone for this loading condition, that is, $a_{o} \leq a \leq a_{c}$ or $0 \leq \mathrm{CTOD} \leq \mathrm{CTOD}_{c}$, is written as

$$
\sigma(x)=\sigma\left(\mathrm{CTOD}_{c}\right)+\frac{\left(f_{t}-\sigma\left(\mathrm{CTOD}_{c}\right)\right)\left(x-a_{0}\right)}{\left(a_{c}-a_{0}\right)},
$$

where, $\sigma\left(\mathrm{CTOD}_{c}\right)$ is the critical values of cohesive stress being at the tip of initialnotch. The value of $\sigma\left(\mathrm{CTOD}_{c}\right)$ is determined by using bilinear softening function:

$$
\sigma\left(\mathrm{CTOD}_{c}\right)=\sigma_{s}\left(w_{s}\right)+\frac{w_{s}-\mathrm{CTOD}_{c}}{w_{s}}\left(f_{t}-\sigma_{s}\left(w_{s}\right)\right) .
$$

(B) When the critical $\mathrm{CTOD}_{c}$ corresponding to maximum load $P_{u}$ is wider than $w_{s}$ as shown in Figure 2(b), the distribution of cohesive stress along the fictitious fracture zone is approximated to be bilinear as shown in Figure 3(b). The variation of cohesive stress along the fictitious fracture zone for this loading condition, also, $a_{o} \leq a \leq a_{c}$ or $0 \leq \mathrm{CTOD} \leq \mathrm{CTOD}_{c}$, is written as

$$
\begin{aligned}
& \sigma_{1}(x)=\sigma\left(\mathrm{CTOD}_{c}\right) \\
& \quad+\left(\sigma_{s}\left(w_{s}\right)-\sigma(w)\right) \frac{\left(x-a_{0}\right)}{\left(a_{s}-a_{0}\right)}, \quad a_{s} \leq x \leq a_{0}, \\
& \sigma_{2}(x)=\sigma_{s}\left(w_{s}\right) \\
& +\left(f_{t}-\sigma_{s}\left(w_{s}\right)\right) \frac{\left(x-a_{s}\right)}{\left(a_{c}-a_{s}\right)}, \quad a_{s} \leq x \leq a_{c} .
\end{aligned}
$$

The value of $\sigma\left(\mathrm{CTOD}_{c}\right)$ is determined by using bilinear softening function:

$$
\sigma\left(\mathrm{CTOD}_{c}\right)=\frac{w_{0}-\mathrm{CTOD}_{c}}{w_{0}-w_{s}} \sigma_{s}\left(w_{s}\right)
$$

The limits of integration of (7) should be taken in two steps: $a_{o} \leq x \leq a_{s}$ for cohesive stress $\sigma_{1}(x)$ and $a_{s} \leq x \leq$ $a_{c}$ for cohesive stress $\sigma_{2}(x)$, respectively. The same Green's function $F(x / a, a / h)$ for a given effective crack extension will 
be determined using (8). The calculated formula is listed as follows:

$$
\begin{aligned}
K_{I}^{\mathrm{c}}= & \int_{a_{0}}^{a_{s}} \frac{2 \sigma_{1}(x) F\left(x / a_{c}, a_{c} / h\right)}{\sqrt{\pi a_{c}}} d x \\
& +\int_{a_{s}}^{a_{c}} \frac{2 \sigma_{2}(x) F\left(x / a_{c}, a_{c} / h\right)}{\sqrt{\pi a_{c}}} d x .
\end{aligned}
$$

The effective crack length at break point $a_{s}$ (shown in Figure $3(\mathrm{~b})$ ) is computed from the following nonlinear expression [4] by substituting COD $\left(a_{s}\right), \mathrm{CMOD}, a_{c}$ and $h$ :

$$
\begin{aligned}
\operatorname{COD}\left(a_{s}\right) & \\
=\operatorname{CMOD} & \left\{\left(1-\frac{a_{s}}{a_{c}}\right)^{2}\right. \\
& \left.+\left(1.018-1.149 \frac{a_{c}}{h}\right)\left[\frac{a_{s}}{a_{c}}-\left(\frac{a_{s}}{a_{c}}\right)^{2}\right]\right\}^{1 / 2},
\end{aligned}
$$

where $\operatorname{COD}\left(a_{s}\right)$ is the crack opening displacement at $a_{s}, a_{c}$ is the effective crack length (according to (1)), and $h$ is the specimen height.

\section{Calculation of Double- $K$ Fracture Parameters}

The two parameters $\left(K_{I}^{\mathrm{ini}}\right.$ and $\left.K_{I}^{\mathrm{un}}\right)$ of double- $K$ fracture criterion for wedge-splitting test are determined using linear elastic fracture mechanics formula given in XU [8]:

$$
\begin{gathered}
K(P, a)=\frac{P \times 10^{-3}}{\mathrm{th}^{1 / 2}} f(\alpha), \\
f(\alpha)=\frac{3.675 \times[1-0.12(\alpha-0.45)]}{(1-\alpha)^{3 / 2}}, \quad \alpha=\frac{a}{h} .
\end{gathered}
$$

The empirical expression (15) is valid within $2 \%$ accuracy for $0.2 \leq \alpha \leq 0.8$.

Equations (15) and (16) can be used in calculation of unstable fracture toughness, $K_{I}^{\text {un }}$ at the tip of effective crack length $a_{c}$, in which $a=a_{c}$ and $P=$ maximum load, $P_{u}$ for TPBT and CT test specimen geometries, respectively. The initiation toughness, $K_{I}^{\mathrm{ini}}$, is calculated using (15) and (16) when the initial cracking load, $P_{\text {ini }}$, at initial crack tip is known. In the present paper, the $P_{\text {ini }}$ is determined by graphical method using the starting point of nonlinearity in $P$-CMOD curve described in the following section.

Generally, for postfire concrete specimens the value of initial fracture toughness $K_{I}^{\mathrm{ini}}$ is far less than the value of critical fracture toughness, $K_{I}^{\text {un }}$, especially for higher temperatures. So much more consideration is put to the critical fracture toughness $K_{I}^{\mathrm{un}}$. In double- $K$ fracture model, the following relation can be employed:

$$
K_{I}^{\mathrm{un}}=K_{I}^{\mathrm{ini}}+K_{I}^{c}
$$

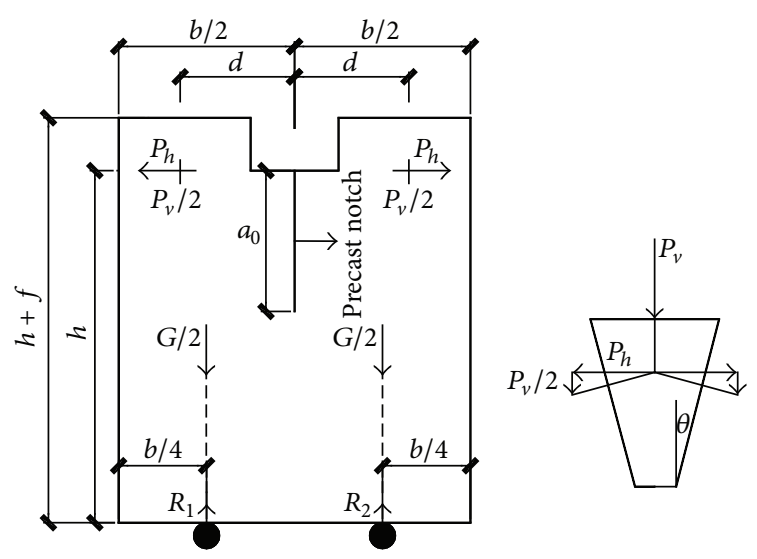

Figure 4: The geometry of specimens.

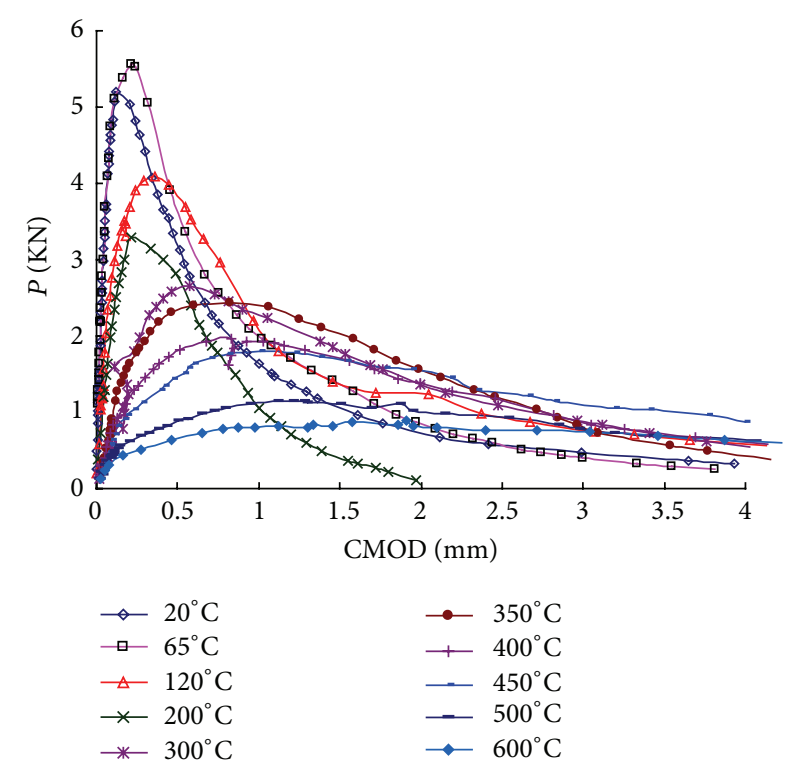

FIgURE 5: $P$ versus CMOD curves of specimens with temperatures.

Here we donate the experimental value, analytical value of critical fracture toughness as $K_{I}^{\mathrm{un}-e}, K_{I}^{\mathrm{un}-A}$, respectively, and from which we would judge the validation of double- $K$ fracture model to the postfire concrete.

\section{Experimental Validation and Comparison of Results}

4.1. Experimental Program and Experimental Phenomena. 50 concrete specimens with the same dimensions $230 \times 200 \times$ $200 \mathrm{~mm}$ were prepared; the geometry of the specimens is shown in Figure $4(b=200 \mathrm{~mm}, d=65 \mathrm{~mm}, h=200 \mathrm{~mm}$, $\left.f=30 \mathrm{~mm}, a_{0}=80 \mathrm{~mm}, \theta=15^{\circ}\right)$. The concrete mix ratios (by weight) were Cement: Sand: Coarse aggregate: Water $=$ $1.00: 3.44: 4.39: 0.80$, with common Portland cement-mixed medium sand and $16 \mathrm{~mm}$ graded coarse aggregate. The compressive strength at 28 days is $34 \mathrm{MPa}$. Nine heating temperatures, ranging from $65^{\circ} \mathrm{C}$ to $600^{\circ} \mathrm{C}\left(T_{m}=65^{\circ} \mathrm{C}\right.$, 


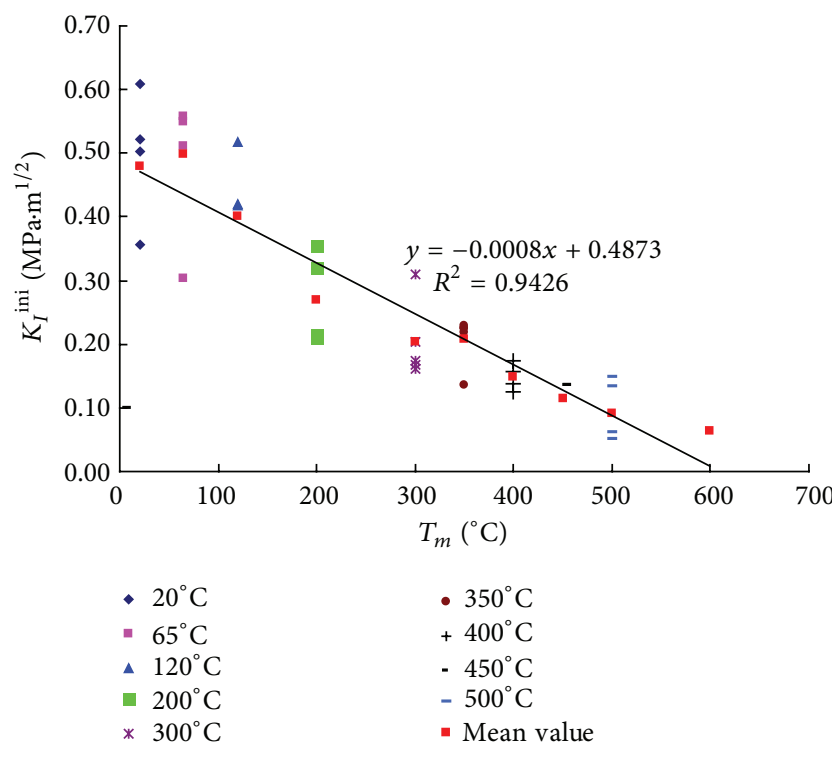

(a) The tendency of $K_{I}^{\mathrm{ini}}$ with $T_{m}$

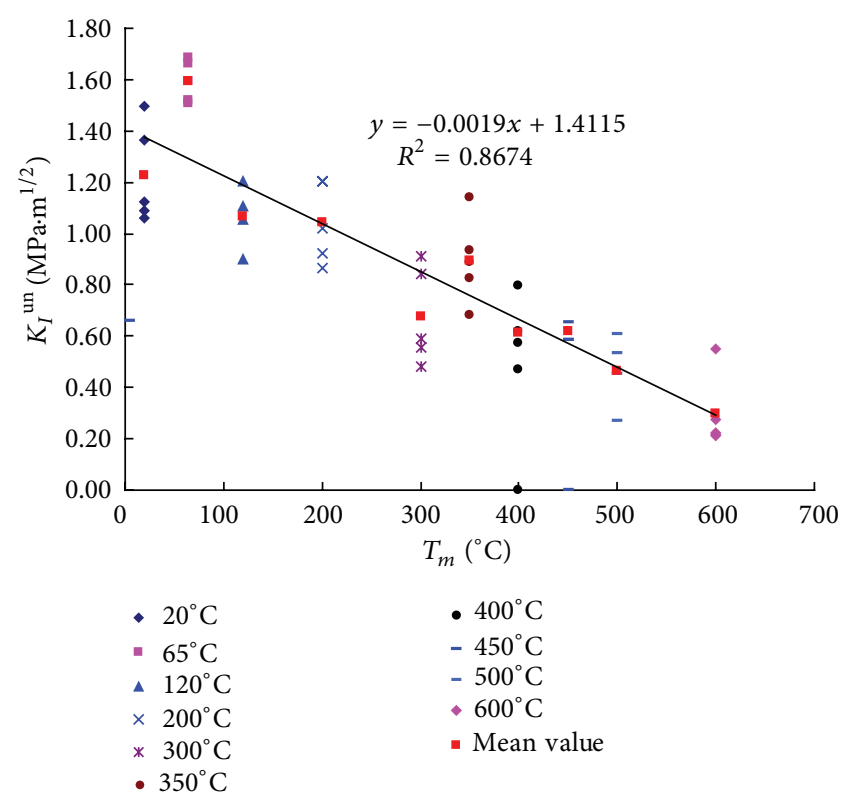

(b) The tendency of $K_{I}^{\mathrm{un}}$ with $T_{m}$

FIgURE 6: The tendency of residual fracture toughness with heating temperatures $T_{m}$.

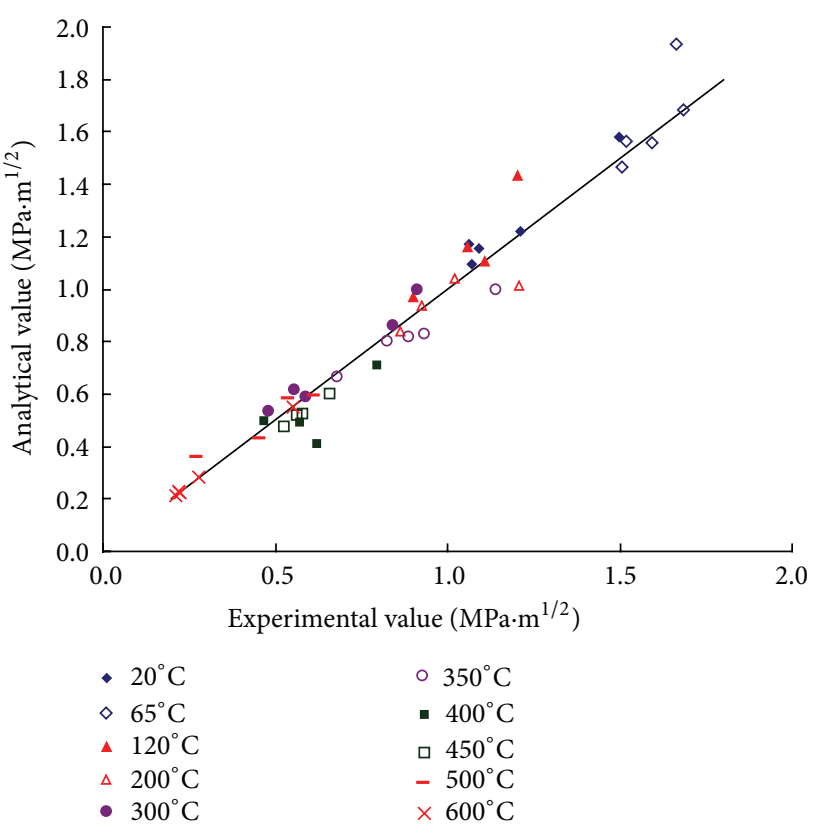

FIGURE 7: Comparison between $K_{I}^{\mathrm{un}-A}$ and $K_{I}^{\mathrm{un}-E}$.

$120^{\circ} \mathrm{C}, 200^{\circ} \mathrm{C}, 300^{\circ} \mathrm{C}, 350^{\circ} \mathrm{C}, 400^{\circ} \mathrm{C}, 450^{\circ} \mathrm{C}, 500^{\circ} \mathrm{C}, 600^{\circ} \mathrm{C}$ ), were adopted with the ambient temperature as a reference. Each wedge splitting specimen was embedded with a thermal couple in the center of specimen for temperature control. An electric furnace with net dimensions $300 \times 300 \times 900 \mathrm{~mm}$ was used for heating. When the designated $T_{m}$ was reached, the furnace was shut down, and the specimens were naturally cooled for 7 days prior to the test. It averagely took 50, 95, $135,182,218,254,294,342$, and 453 mins for the specimens to reach the final temperatures, respectively (from $65^{\circ} \mathrm{C}$ to $600^{\circ} \mathrm{C}$ ). The detailed experimental information would be found elsewhere [22].

4.2. Experimental Results. Figure 5 shows typical complete load-displacement curves for different heating temperatures up to $600^{\circ} \mathrm{C}$. The figure shows that the ultimate load $P_{u}$ decreases significantly with increasing temperatures $T_{m}$, whereas the crack-mouth opening displacement (CMOD) increases with $T_{m}$. The initial slope of ascending branches decreases with heating temperatures, and the curves become gradually shorter and more extended.

The recorded maximum load $P_{u}$, the recorded crack mouth opening displacement $\mathrm{CMOD}_{c}$ at $P_{u}$, the calculated crack tip opening displacement $\mathrm{CTOD}_{c}$ based on (14), the initial cracking load $P_{\text {ini }}$ determined by graphical method, the calculated residual Young's modulus $E$ based on (2), the double- $K$ fracture parameters, that is, $K_{I}^{\text {ini }}$ and $K_{I}^{\text {un- } E}$, and the residual fracture energy $G_{F}$ are summarized in Table 1 . Here we only list part of the statistics.

4.3. Discussion. In order to express the influence on the residual fracture toughness in detail, Figure 6 plots the tendency of initial fracture toughness $K_{I}^{\text {ini }}$ and the unstable fracture toughness $K_{I}^{\mathrm{un}}$ with heating temperatures $T_{m}$. It is concluded that the toughness of the two fractures decreases monotonously with $T_{m}$ because of the thermal damage induced by the heating temperatures.

The initial fracture toughness continuously decreases from $0.498 \mathrm{MPa} \cdot \mathrm{m}^{1 / 2}$ at room temperature to $0.269 \mathrm{MPa} \cdot \mathrm{m}^{1 / 2}$ 
at $200^{\circ} \mathrm{C}, 0.115 \mathrm{MPa} \cdot \mathrm{m}^{1 / 2}$ at $450^{\circ} \mathrm{C}$, and finally $0.064 \mathrm{MPa}$. $\mathrm{m}^{1 / 2}$ at $600^{\circ} \mathrm{C}$, with a significant loss of $0.434 \mathrm{MPa} \cdot \mathrm{m}^{1 / 2}$ or $96 \%$. The unstable fracture toughness decreases from $1.186 \mathrm{MPa} \cdot \mathrm{m}^{1 / 2}$ at room temperature to $0.297 \mathrm{MPa} \cdot \mathrm{m}^{1 / 2}$ at $600^{\circ} \mathrm{C}$, with a significant loss of $0.889 \mathrm{MPa} \cdot \mathrm{m}^{1 / 2}$ or $75 \%$.

Comparing the results shown in Table 1, it can be known that the value of $K_{I}^{\text {un- } A}$ evaluated by (17) has good coincidence with the one calculated by inserting the values of $P_{\max }$ and $a_{c}=h$ into (15), that is, the critical fracture toughness from analytical and experimental method. Figure 7 shows the relationship between the two parameters. In totally 45 effective specimens, the deviation between $K_{I}^{\mathrm{un}-A}$ and $K_{I}^{\mathrm{un}-E}$ of 22 specimens is below $5 \%$ and of 40 specimens is below $15 \%$, which accounts for $89 \%$ of total specimens.

\section{Conclusion}

The determination of residual fracture parameter using analytical method is carried out in present research. In calculating the cohesive fracture toughness, two conditions are divided at critical load: for specimens subjected to temperatures less than $120^{\circ} \mathrm{C}$, the critical CTOD ${ }_{c}$ is less than $w_{s}$, whereas, for temperatures higher than $120^{\circ} \mathrm{C}$, the critical CTOD ${ }_{c}$ corresponding to maximum load $P_{u}$ is wider than $w_{s}$. This part of work would be a useful supplement to the existed analysis.

Wedge-splitting tests with ten temperatures varying from $20^{\circ} \mathrm{C}$ to $600^{\circ} \mathrm{C}$ are implemented. The complete load-crack opening displacement curves are obtained and the initial and critical fracture toughness could be calculated experimentally.

The validation of double- $K$ fracture model to the postfire concrete specimens is proved. In totally 45 effective specimens, the deviation between analytical value $K_{I}^{\mathrm{un}-A}$ and experimental $K_{I}^{\mathrm{un}-E}$ of 22 specimens is below $5 \%$ and of 40 specimens is below $15 \%$, which accounts for $89 \%$ of total specimens.

\section{Conflict of Interests}

The authors declare that there is no conflict of interests regarding the publication of this paper.

\section{Acknowledgment}

The State Laboratory of Disaster Reduction in Civil Engineering (SLDRCE09-D-02) has supported this research.

\section{References}

[1] S. Xu and H. W. Reinhardt, "Determination of double-K criterion for crack propagation in quasi-brittle fracture-part I: experimental investigation of crack propagation," International Journal of Fracture, vol. 98, no. 2, pp. 111-149, 1999.

[2] X. U. Shilang and H. W. Reinhardt, "Determination of double$\mathrm{K}$ criterion for crack propagation in quasi-brittle fracture-part II: analytical evaluating and practical measuring methods for three-point bending notched beams," International Journal of Fracture, vol. 98, no. 2, pp. 151-177, 1999.

[3] S. Xu and H. W. Reinhardt, "Determination of double-K criterion for crack propagation in quasi-brittle fracture-part III: compact tension specimens and wedge splitting specimens," International Journal of Fracture, vol. 98, no. 2, pp. 179-193, 1999.

[4] Y. S. Jenq and S. P. Shah, "A Fracture toughness criterion for concrete," Engineering Fracture Mechanics, vol. 21, no. 5, pp. 1055-1069, 1985.

[5] Y. Murakami, Stress Intensity Factors Handbook, Pergamon Press, London, 1987.

[6] S. Kumar and S. V. Barai, "Influence of specimen geometry and size-effect on the KR-curve based on the cohesive stress in concrete," International Journal of Fracture, vol. 152, no. 2, pp. 127-148, 2008.

[7] S. Kumar and S. V. Barai, "Influence of specimen geometry on determination of double-K fracture parameters of concrete: a comparative study," International Journal of Fracture, vol. 149, no. 1, pp. 47-66, 2008.

[8] B. L. Karihaloo and P. Nallathambi, "Size-effect prediction from effective crack model for plain concrete," Materials and Structures, vol. 23, no. 3, pp. 178-185, 1990.

[9] Z. P. Bazand and P. C. Prat, "Effect of temperature and humidity on fracture energy of concrete," ACI Materials Journal, vol. 85, no. 4, pp. 262-271, 1988.

[10] G. Baker, "The effect of exposure to elevated temperatures on the fracture energy of plain concrete," Materials and Structures, vol. 29, no. 6, pp. 383-388, 1996.

[11] B. Zhang, N. Bicanic, C. J. Pearce, and G. Balabanic, "Residual fracture properties of normal- and high-strength concrete subject to elevated temperatures," Magazine of Concrete Research, vol. 52, no. 2, pp. 123-136, 2000.

[12] C. V. Nielsen and N. Bicanic, "Residual fracture energy of highperformance and normal concrete subject to high temperatures," Materials and Structures, vol. 36, no. 8, pp. 515-521, 2003.

[13] B. Zhang and N. Bicanic, "Fracture energy of high-performance concrete at high temperatures up to $450^{\circ} \mathrm{C}$ : the effects of heating temperatures and testing conditions (hot and cold)," Magazine of Concrete Research, vol. 58, no. 5, pp. 277-288, 2006.

[14] G. Prokopski, "Fracture toughness of concretes at high temperature," Journal of Materials Science, vol. 30, no. 6, pp. 1609-1612, 1995.

[15] H. Abdel-Fattah and S. A. Hamoush, "Variation of the fracture toughness of concrete with temperature," Construction and Building Materials, vol. 11, no. 2, pp. 105-108, 1997.

[16] P. E. Petersson, "Crack growth and development of fracture zones in plain concrete and similar materials," Report TVBM1006, Division of Building Materials, Lund Institute of Technology, Lund, Sweden, 1981.

[17] V. S. Gopalaratnam and S. P. Shah, "Softening response of plain concrete in direct tension," Journal of the American Concrete Institute, vol. 82, no. 3, pp. 310-323, 1985.

[18] H. W. Reinhardt, H. A. W. Cornelissen, and D. A. Hordijk, "Tensile tests and failure analysis of concrete," Journal of Structural Engineering, vol. 112, no. 11, pp. 2462-2477, 1986.

[19] H. K. Hilsdorf and W. Brameshuber, "Code-type formulation of fracture mechanics concepts for concrete," International Journal of Fracture, vol. 51, no. 1, pp. 61-72, 1991.

[20] D. V. Phillips and Z. Zhang, "Direct tension tests on notched and un-notched plain concrete specimens," Magazine of Concrete Research, vol. 45, no. 162, pp. 25-35, 1993. 
[21] H. Tada, P. C. Paris, and G. Irwin, The Stress Analysis of Cracks Handbook, Paris Productions Inc., St. Louis, Mo, USA, 1985.

[22] J. T. Yu, K. Q. Yu, and Z. D. Lu, "Residual fracture properties of concrete subjected to elevated temperatures," Materials and Structures, vol. 45, no. 8, pp. 1155-1165, 2012. 

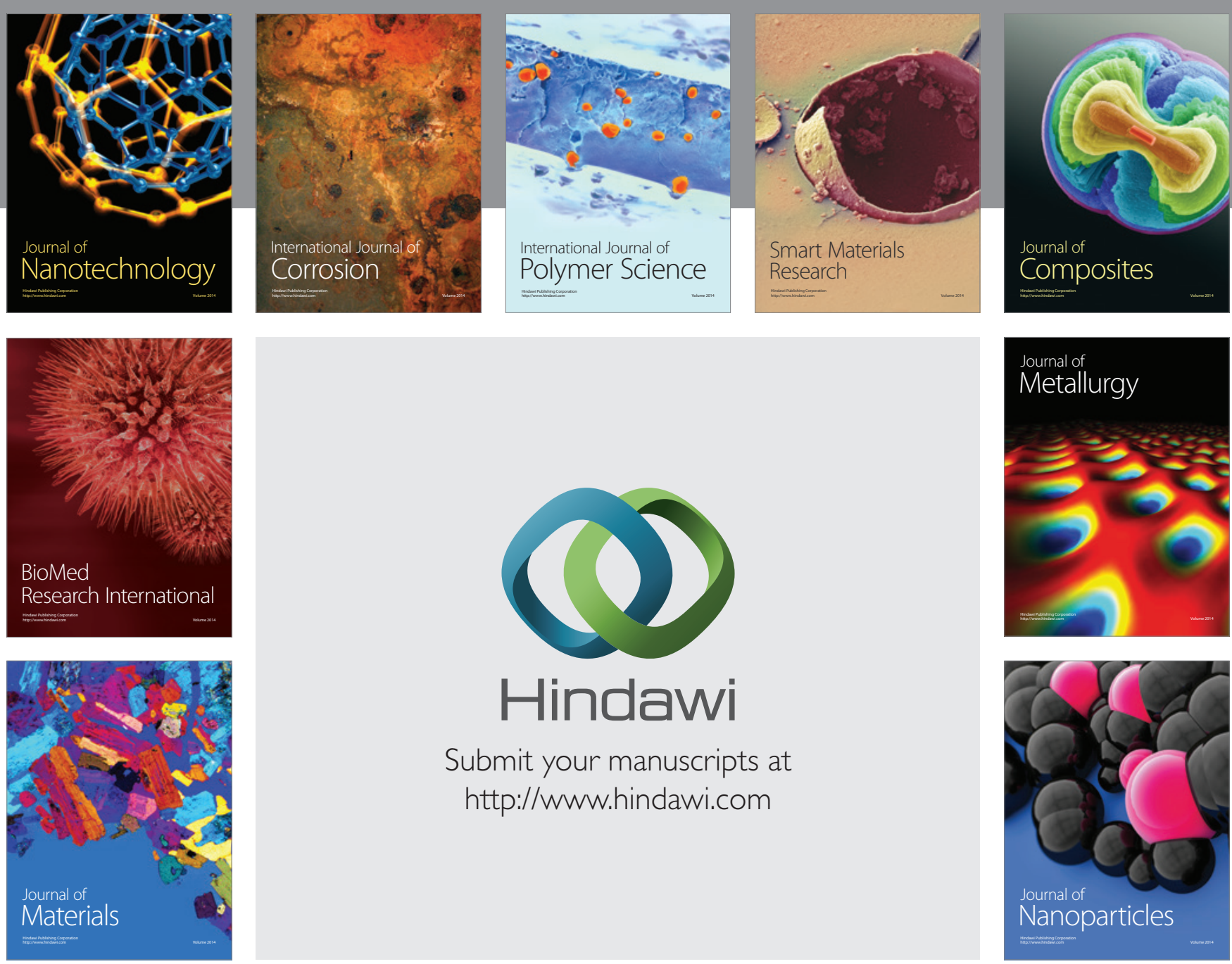

Submit your manuscripts at http://www.hindawi.com
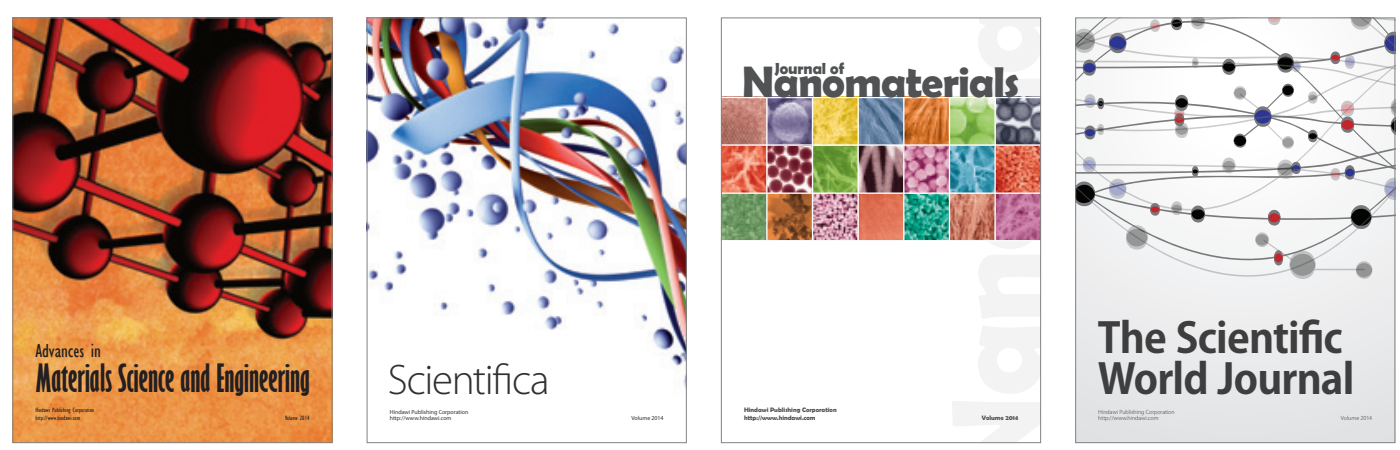

\section{The Scientific World Journal}
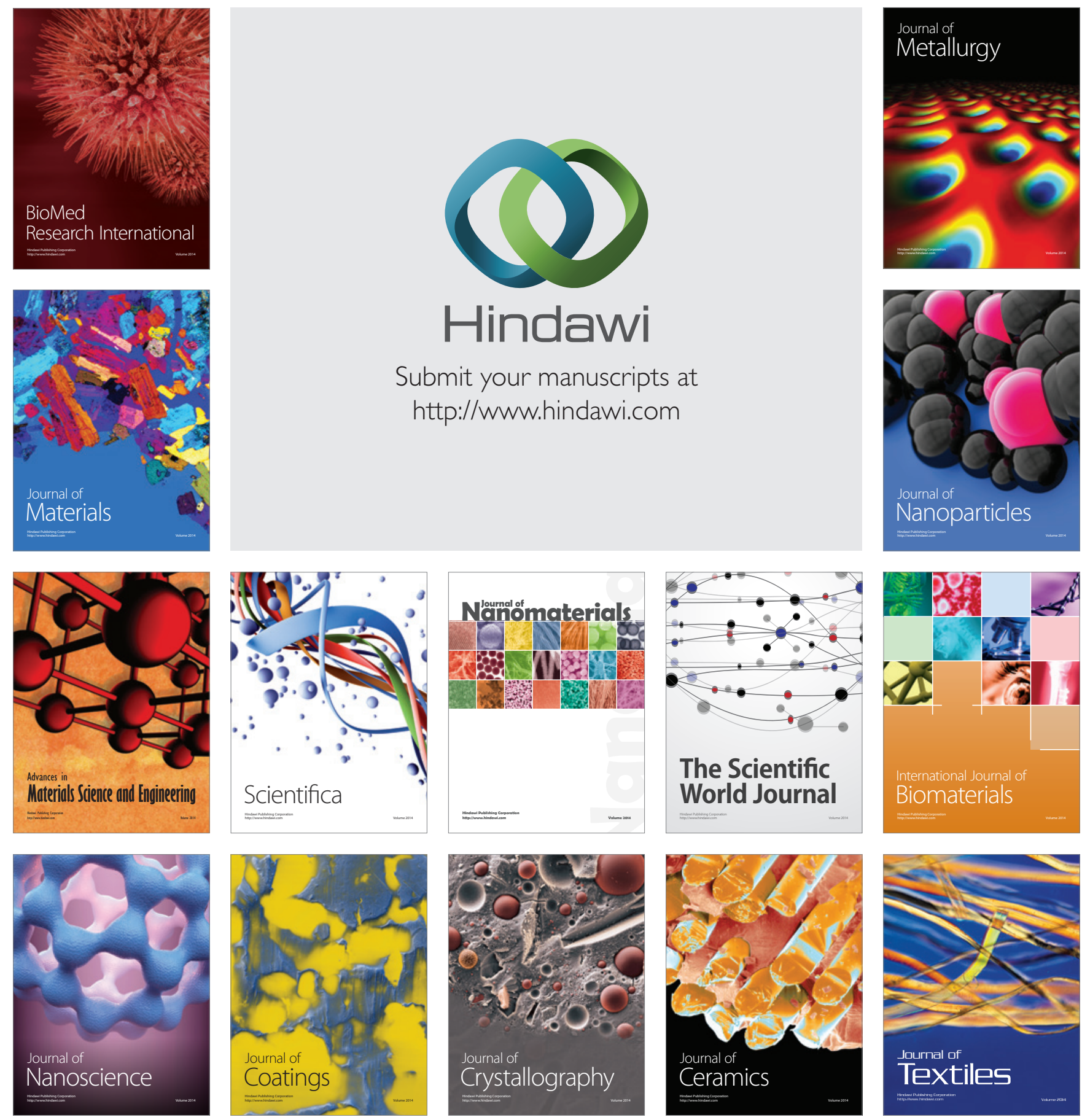